\title{
Multimaterial photonic crystal fibers
}

\author{
Markos, Christos; Petersen, Christian Rosenberg
}

\section{Published in:}

Proceedings of SPIE

Link to article, DOI:

$10.1117 / 12.2290367$

Publication date:

2018

Document Version

Publisher's PDF, also known as Version of record

Link back to DTU Orbit

Citation (APA):

Markos, C., \& Petersen, C. R. (2018). Multimaterial photonic crystal fibers. In Proceedings of SPIE (Vol. 10528). [105280V] SPIE - International Society for Optical Engineering. Proceedings of SPIE - The International Society for Optical Engineering https://doi.org/10.1117/12.2290367

\section{General rights}

Copyright and moral rights for the publications made accessible in the public portal are retained by the authors and/or other copyright owners and it is a condition of accessing publications that users recognise and abide by the legal requirements associated with these rights.

- Users may download and print one copy of any publication from the public portal for the purpose of private study or research.

- You may not further distribute the material or use it for any profit-making activity or commercial gain

- You may freely distribute the URL identifying the publication in the public portal

If you believe that this document breaches copyright please contact us providing details, and we will remove access to the work immediately and investigate your claim. 


\section{Multimaterial photonic crystal fibers}

Christos Markos, Christian Rosenberg Petersen

Christos Markos, Christian Rosenberg Petersen, "Multimaterial photonic crystal fibers," Proc. SPIE 10528, Optical Components and Materials XV, 105280V (22 February 2018); doi: 10.1117/12.2290367

SPIE. Event: SPIE OPTO, 2018, San Francisco, California, United States 


\title{
Multimaterial Photonic Crystal Fibers
}

\author{
Christos Markos* and Christian Rosenberg Petersen \\ DTU Fotonik, Department of Photonics Engineering, Technical University of Denmark, 2800 Kgs. \\ Lyngby, Denmark
}

\begin{abstract}
One of the main advantages of photonic crystal fibers (PCFs) is their ability to host novel functional materials in the airholes of the cladding. Here, we demonstrate a unique post-processing method which allows the integration of materials with significantly different thermo-mechanical properties inside the voids of silica PCF. We first present the material properties of silica, $\mathrm{As}_{2} \mathrm{Se}_{3}$ and polydimethylsiloxane (PDMS) in terms of their refractive indices and viscosity profile. The latter suggests that the proposed materials are not suitable for direct fiber drawing and thus we present the development of a multi-material $\mathrm{As}_{2} \mathrm{Se}_{3} / \mathrm{PDMS} /$ Silica PCF based on a solution-processed and pressure-assisting method. The integration of both $\mathrm{As}_{2} \mathrm{Se}_{3}$ chalcogenide glass films and PDMS was made in ambient conditions using a costeffective approach. The deposition of the high-index chalcogenide glass films revealed distinct resonances in the visible and near-infrared region while the high thermo-optic coefficient of PDMS provides the ability to thermally control the intensity of the antiresonant bands. The proposed method opens new directions towards multimaterial silica-based PCFs for novel tunable devices and sensors.
\end{abstract}

Keywords: Multimaterial, Photonic crystal fiber, chalcogenide, PDMS, soft-glass, tunable devices

\section{INTRODUCTION}

PCFs were first proposed in 1991 by Philip St J. Russell [1] and later realized experimentally in 1996 [2]. Since then, this unique class of optical fibers has revolutionized the field of fiber optics attracting the scientific attention of several research groups around the globe. PCFs are usually made from a single material which can be either glass [2, 3], polymer [4, 5], or even a combination of two materials [6, 7]. The fiber structure consists of a hexagonal array of air holes forming a honeycomb photonic air-cladding that surrounds the solid core formed by a missing air hole, which runs along the entire length of the fiber. PCFs have been divided into solid-cores PCF [8], which guides light through the core-cladding refractive index contrast, and hollow-core (HC) PCF, where the guidance relies on the bandgap effect or antiresonant reflecting optical waveguide (ARROW) model [9, 10]. In 2011, a simplified version of the conventional HC photonic bandgap fiber (HC-PBG) was reported by Pryamov et al. in which the honeycomb structure of the cladding can be replaced with a single ring of capillaries thus reducing the fabrication complexity of the fiber [11]. The proposed fiber design, known as negative-curvature antiresonant fiber (NC-ARF) [12], has attracted a lot of attention mainly for high power laser applications [13] and for gas-based extreme nonlinear optics both in the UV but also in the mid-IR wavelength range [14, 15].

Since their inception, PCFs have created new possibilities to control and modify the guiding properties in ways not possible in standard optical fibers. For example, PCF can be endlessly single-mode (supports only a single transverse spatial mode at all wavelengths) by maintaining the relation between hole size (d) and hole distance i.e. pitch $(\Lambda) \mathrm{d} / \Lambda$ less than 0.44 [8]. In 2000, it was shown that the zero-dispersion wavelength can be shifted to short wavelengths by changing the size hole and the pitch of the microstructure [16]. The ability to tailor the dispersion of the PCF had a direct impact in the fiber laser community and was the enabling technology for efficient supercontinuum generation [16].

However, another important advantage of PCFs compared to standard all-solid fibers, is that they can act as "substrate" where the cladding holes of the fiber can host novel functional optical materials creating a new branch of research known as hybrid photonic crystal fiber as described in a recent extensive review article [17]. The first hybrid PCF was demonstrated by Westbrook et al. [18] who reported the ability to tune the cladding-mode resonances by simply varying the external temperature in a solid-core fiber with polymer-infused holes. Since then there has been several reports on hybrid PCFs where both solid- as well as hollow-core PCFs have been combined with advanced materials [17].

*chmar@fotonik.dtu.dk; phone +45 45256387; fax +45 45936581; fotonik.dtu.dk

Optical Components and Materials XV, edited by Shibin Jiang, Michel J. F. Digonnet, Proc. of SPIE Vol. 10528, 105280V (C) 2018 SPIE · CCC code: 0277-786X/18/\$18 · doi: 10.1117/12.2290367 
In 2011, Granzow et al. interestingly demonstrated the infiltration of chalcogenide glass inside a solid-core PCF using the pressure-assisted method [19]. They reported that the high-index glass rods introduce strong resonances from $\sim 450$ up to $900 \mathrm{~nm}$ wavelength. A year later, Markos et al. showed for the first time a novel approach of integrating chalcogenide glass nanolayers inside the PCF using a solution-processed approach [21]. This approach was applied later to report thermally tunable PCF-based devices [22, 23]. It should be noted that chalcogenide glasses have unique optical properties such as photo-sensitivity under illumination near their bandgap, transparency in the mid-infrared, and high nonlinearity. Nowadays, the main use of this category of glasses is for mid-IR supercontinuum generation [20] and other nonlinear applications.

Multimaterial fibers mainly refer to structures compromising more than two distinct materials as described in [17, 24]. Since then, there has been an extensive number of interesting results based on multimaterial fibers for optoelectronic applications and more recently for controlled sphere manufacturing $[25,26]$. In this work, we report for the first time the combination of the solution-processed and the pressure-assisted method to develop a multimaterial PCF based on silica, stoichiometric $\mathrm{As}_{2} \mathrm{Se}_{3}$ and PDMS elastomer. PDMS is widely used in in opto/microfluidics because it has excellent material properties, such as transparency over a wide range of wavelengths in the visible, refractive index (around 1.41) less than fused silica, high elasto-optic and thermo-optic coefficients, biocompatibility, etc. [27]. Moreover it has good mechanical properties due to low Young's modulus which makes it soft and deformable with very low shrinkage and combined with its ease fabrication procedure is a potential active material for tunable devices and sensing applications. PDMS has been already combined with silica PCFs for thermo-tunable devices and sensors [28-30].

Here we show that the high-index chalcogenide glass introduces ARROW guidance and due to the high thermo-optic coefficient of PDMS [28-30], it is possible to control the intensity of the antiresonant transmission windows. The following Figure 1 shows the schematic representation of the proposed multimaterial structure where Fig 1 (a), (b), and (c) is the initial PCF, the PCF after the integration of the chalcogenide nanofilms, and the PCF after infiltration of PDMS, respectively.
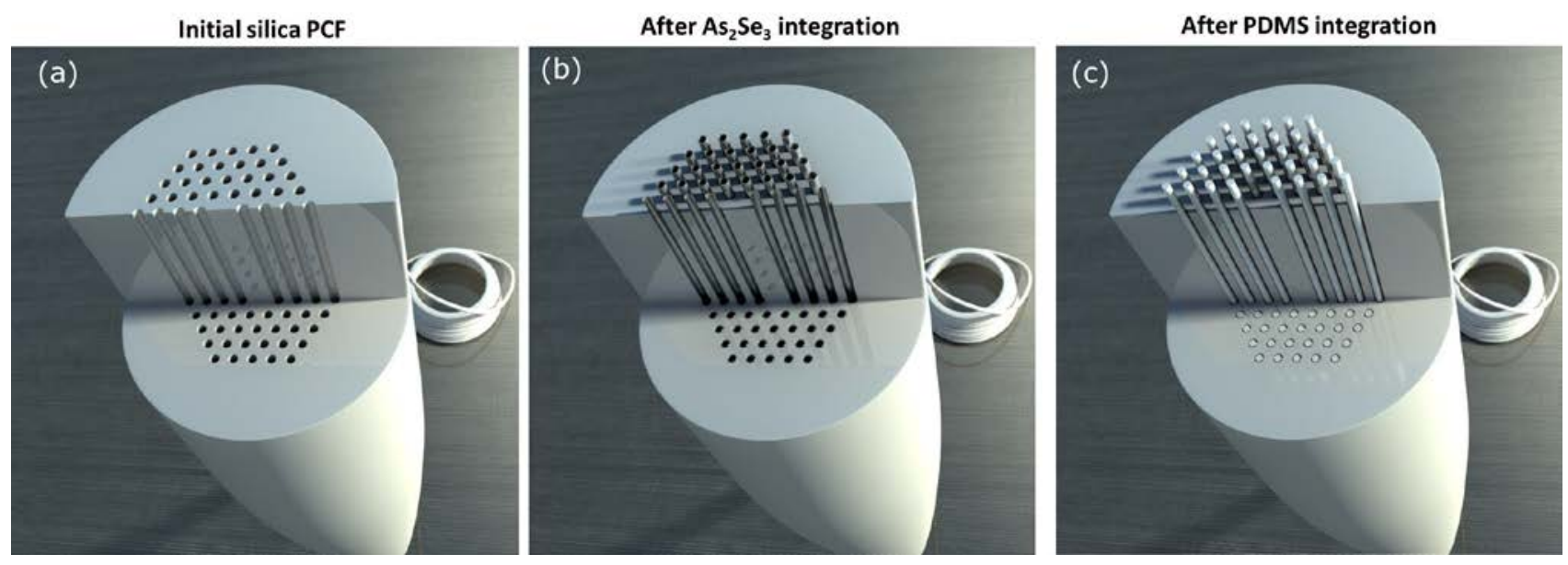

Figure 1. Schematic representation of the proposed multimaterial structure. (a) Initial silica PCF, (b) the PCF after the integration of the $\mathrm{As}_{2} \mathrm{Se}_{3}$ and (c) the final multimaterial structure (silica, $\mathrm{As}_{2} \mathrm{Se}_{3}$ and PDMS).

\section{MATERIAL PREPARATION AND CHARACATERIZATION}

The solid-core PCF (LMA-10) used in our experiments is commercially available and provided by NKT Photonics A/S. The fiber has 7-rings of air-holes, a core diameter of around $10 \mu \mathrm{m}$, and cladding air-hole diameters $\mathrm{d} \sim 3.5 \mu \mathrm{m}$ as shown in the scanning electron microscopy (SEM) image in Fig. 2 (a). The fiber has a relative hole size $d / \Lambda<0.42$ ensuring that it is endlessly single-moded [8].

The amorphous stoichiometric $\mathrm{As}_{2} \mathrm{Se}_{3}$ bulk pieces were supplied from Alfa Aesar (purity (99.999\%)). The bulk $\mathrm{As}_{2} \mathrm{Se}_{3}$ glass was grinded into fine powder using a ceramic mortar in a Nitrogen environment to avoid oxidation of the material and then dissolved in ethylenediamine (EDA) (purity >99\%) inside a sealed glass flask to prevent the solvent from evaporation. The dissolution procedure required approximately 5 hours in order to ensure complete dissolution of the 
bulk glass. It should be noted that the glass quality used in our experiments could be further improved by using high purity chalcogenide glass prepared based on the melt-quenching technique. Using the capillary forces, the PCFs were infiltrated over $\sim 10 \mathrm{~cm}$ and rested at room temperature for $48 \mathrm{~h}$ and then annealed at $\sim 90^{\circ} \mathrm{C}$ for $24 \mathrm{~h}$. Finally the samples were further annealed close to the Tg of the chalcogenide glass for $72 \mathrm{~h}$ in order to remove the solvent and leave only the glass layer. However, it should be emphasized that the solvent is chemically linked with the glass and cannot be completely removed [31]. Figure 2 (b) shows the solution in a flask after the complete dissolution of the $\mathrm{As}_{2} \mathrm{Se}_{3}$ glass pieces.
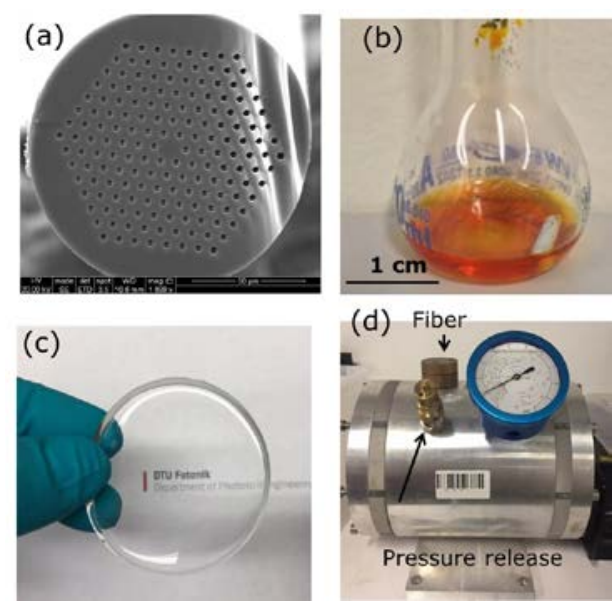

Figure 2. (a) SEM image of the LMA-10. (b) Image of the dissolved $\mathrm{As}_{2} \mathrm{Se}_{3}$ glass in EDA solution. (c) PDMS elastomer after curing. (d) Custom-made pressure chamber used to infiltrate the PDMS inside the fiber.

PDMS (Sylgard 184-Dow Corning) was prepared by mixing elastomer and curing agent at 10:1 ratio [28-30]. Using a custom-made pressure chamber (see Figure 2 (d)), the material was infiltrated inside the $\mathrm{As}_{2} \mathrm{Se}_{3} /$ silica PCF under 20 bars pressure for approximately 2 hours and left in ambient conditions for 28 hours. Figure 2 (c) shows the PDMS material after curing. Figure 3 (a) and (b) shows the cross-section of the $\mathrm{As}_{2} \mathrm{Se}_{3} /$ silica PCF of the core and a single hole, respectively, indicating the formation of the nanometer-scale $\mathrm{As}_{2} \mathrm{Se}_{3}$ glass layer. Similarly, Figure (c) and (d) shows the SEM images of the fiber of the full cross-section and the core of the fiber after the infiltration of PDMS.
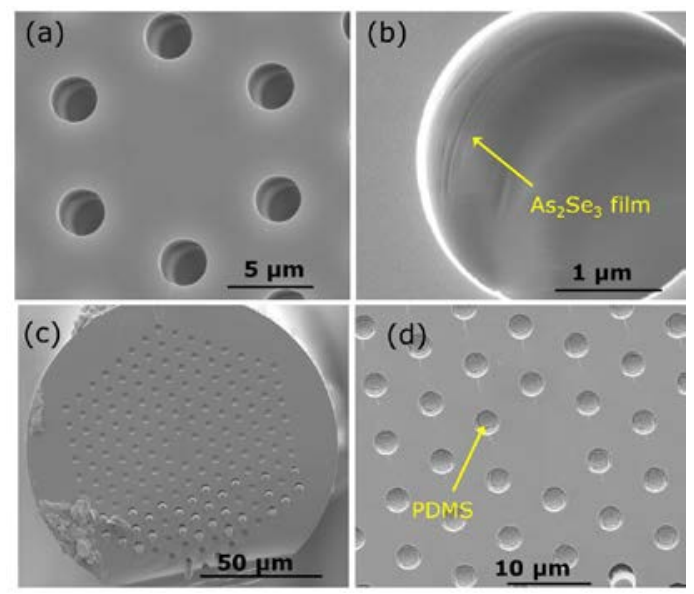

Figure 3. SEM images of the (a) PCF core with the formed films, (b) a single magnified hole indicating the $\mathrm{As}_{2} \mathrm{Se}_{3}$ nanolayer, (c) the full cross-section of the multimaterial PCF and (d) magnified section of the core.

We characterized the bulk materials in terms of their refractive indices using ellipsometry (J.A.Woollam). Figure 4 (a) shows the refractive indices of the bulk PDMS and $\mathrm{As}_{2} \mathrm{Se}_{3}$ illustrating the significant difference in refractive index between the two. The high index glass introduces ARROW guidance as previously described in [21-23]. On the other hand, PDMS has a lower refractive index than silica and therefore does not affect the guiding mechanism [28-30]. From 
the perspective of direct fiber drawing, the temperature dependence of viscosity is the most important parameter. Figure 4 (b) shows the viscosity of PDMS and silica indicating the significant difference between the two, thus making it impossible to use conventional fiber drawing methods to fabricate the proposed multimaterial structure. Therefore, the current approach is perhaps the only way to develop multimaterial PCFs based on materials of completely different thermo-mechanical properties.
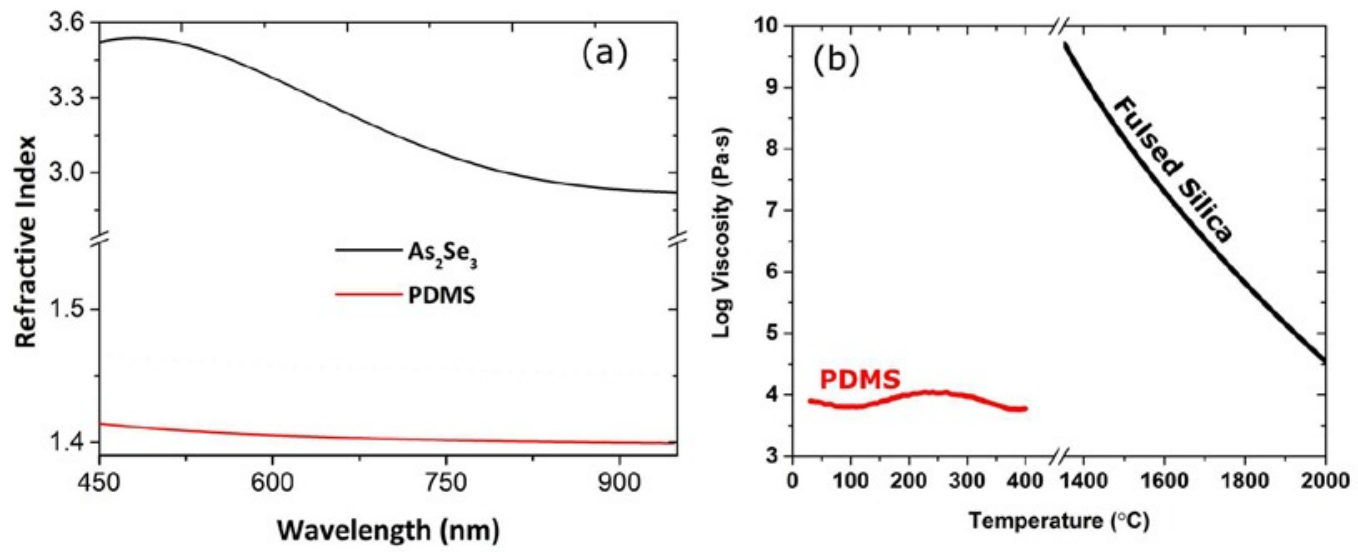

Figure 4. (a) Refractive index profile of $\mathrm{As}_{2} \mathrm{Se}_{3}$ and PDMS determined with ellipsometry. (b) Viscosity profile of PDMS and fused silica [extracted from ref. 32] indicating their significant temperature difference.

\section{RESULTS}

The characterization of the multimaterial PCF was made using a high power supercontinuum source (SuperK Versa, NKT Photonics A/S). The light was launched into the fiber using a 40x microscope objective and the output beam was collimated with a 60x objective and focused into a multimode fiber (60 $\mu \mathrm{m}$ core size) using a 10x objective. Finally, the spectra were recorded using an optical spectrum analyser (OSA). The thermal characterization of the fiber was performed by placing the fiber in a controlled heat element (Linkam MC60). Figure 5 (a) shows the initial spectrum of the multimaterial PCF at room temperature. As it can be seen, the fiber has resonances as strong as $\sim 40 \mathrm{~dB}$ from $\sim 500$ up to $1600 \mathrm{~nm}$ wavelength due to the high-index chalcogenide glass nanolayers [21-23]. Figure 5 (b) shows how the intensity of every antiresonance increases as temperature increases from room temperature up to $80^{\circ} \mathrm{C}$. It should be noted that both silica and $\mathrm{As}_{2} \mathrm{Se}_{3}$ have very low thermo-optic coefficients [23, 33] and therefore the variations in the spectra are solely attributed to the highly negative thermo-optic coefficient of PDMS [29].
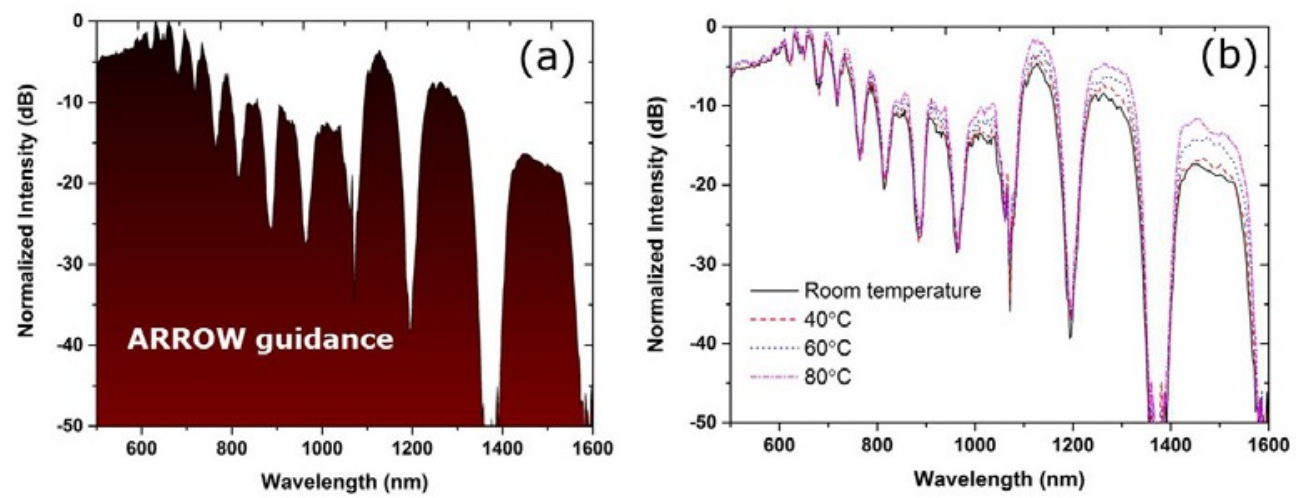

Figure 5. Transmission spectrum of the multimaterial PCF at room temperature. (b) Temperature dependence of the intensity of the antiresonant bands from room up to $80^{\circ} \mathrm{C}$.

\section{CONCLUSION}

In conclusion, we have reported the combination of a solution-processed approach with the pressure-assisted method for the development of a multimaterial PCF based on the $\mathrm{As}_{2} \mathrm{Se}_{3}$ chalcogenide glass and PDMS elastomer. The high-index 
glass layers revealed distinct resonances from 500 up to $1600 \mathrm{~nm}$ while PDMS allowed control of the intensity of the antiresonant bands. The sensitivity and performance of the proposed device can be further increased by optimizing the fiber structure and material combination. The current approach constitutes an efficient way for the development of multimaterial PCF structures based on silica and materials with different thermo-mechanical properties.

\section{ACKNOWLEDGEMENTS}

C.M. would like to acknowledge financial support from the Danish Council for Independent Research (4184-00359B). The authors would also like to acknowledge the Innovation Fund Denmark (4107-00011A).

\section{REFERENCES}

[1] Russell, P. and Dettmer R., "A neat idea [photonic crystal fibre]," IEE Review, 47(5), 19 - 23 (2001).

[2] Knight, J. C., Birks, T. A., Russell, P. St. J. and Atkin, D. M., "All-silica single-mode optical fiber with photonic crystal cladding," Opt. Lett. 21 (19), 1547-1549 (1996).

[3] Monro, T.M., West, Y.D., Hewak, D.W., Broderick and N. G. R. and Richardson, D. J., "Chalcogenide holey fibres," Electron. Lett. 36(24), 1998-2000 (2000).

[4] van Eijkelenborg, M., Large, M. C. J., Argyros, A., Zagari, J., Manos, S., Issa, N. A., Bassett, I., Fleming, S., McPhedran, R. C., Martijn de Sterke, C. and Nicorovici, N. A. P., "Microstructured polymer optical fibre," Opt. Express 9(7), 319-327 (2001).

[5] Woyessa, G., Fasano, A., Markos, C., Rasmussen, H.K. and Bang, O., "Low loss polycarbonate polymer optical fiber for high temperature FBG humidity sensing," IEEE Photonics Technol. Lett. 29(7), 575-578 (2017).

[6] Cerqueira, S. A., Luan, F., Cordeiro, C.M.B., George, A. K. and Knight, J.C., "Hybrid photonic crystal fiber," Opt. Express 14 (2), 926-931 (2006).

[7] Woyessa, G., Pedersen, J. K.M., Fasano, A., Nielsen, K., Markos, C., Rasmussen, H. K. and Bang, O. "ZeonexPMMA microstructured polymer optical FBGs for simultaneous humidity and temperature sensing, " Opt. Lett. 42 (6), 1161-1164 (2017).

[8] Birks, T.A., Knight, J.C. and Russell, P. St. J., "Endlessly single-mode photonic crystal fiber," Opt. Lett. 22 (13), 961-963 (1997).

[9] Cregan, R. F., Mangan, B.J., Knight, J.C., Birks, T.A., Russell, P. St. J., Roberts, P. J. and Allan, D. C., "Singlemode photonic band gap guidance of light in air," Science 285(5433), 1537-1539 (1999)

[10] Litchinitser, N. M., Abeeluck, A. K., Headley, C. and Eggleton, B. J., "Antiresonant reflecting photonic crystal optical waveguides," Opt. Lett. 27(18), 1592-1594 (2002)

[11] Pryamikov, A. D., Biriukov, A. S., Kosolapov, A. F., Plotnichenko, V. G., Semjonov, S. L. and Dianov, E. M., "Demonstration of a waveguide regime for a silica hollow-core microstructured optical fiber with a negative curvature of the core boundary in the spectral region > $3.5 \mu \mathrm{m}$," Opt. Express 19(2), 1441-1448 (2011).

[12] Wei, C., Weiblen, R. J., Menyuk, C. R. and Hu, J., "Negative curvature fibers," Adv. Opt. Photon. 9(3), 504-561 (2017).

[13] Michieletto, M., Lyngsø, J. K., Jakobsen, C., Lægsgaard, J., Bang, O. and Alkeskjold, T. T., "Hollow-core fibers for high power pulse delivery," Opt. Express 24 (7), 7103-7119 (2016).

[14] Cassataro, M., Novoa, D., Günendi, M. C., Edavalath, N. N., Frosz, M. H., Travers, J. C. and Russell, P. St.J., "Generation of broadband mid-IR and UV light in gas-filled single-ring hollow-core PCF," Opt. Express 25 (7), 7637-7644 (2017).

[15] Habib, Md. S., Markos, C., Bang, O. and Bache, M., "Soliton-plasma nonlinear dynamics in mid-IR gas-filled hollow-core fibers," Opt. Lett. 42 (11), 2232-2235 (2017).

[16] Knight, J. C., Arriaga, J., Birks, T. A., Ortigosa-Blanch, A., Wadsworth, W. J. and Russell, P. St. J., "Anomalous dispersion in photonic crystal fiber," IEEE Photonics Technol. Lett. 12(7), 807-809 (2000).

[17] Markos, C., Travers, J. C., Abdolvand, A., Eggleton, B. J. and Bang, O., "Hybrid photonic-crystal fiber," Rev. Mod. Phys. 89(4), 045003 (2017).

[18] Westbrook, P. S., Eggleton, B. J., Windeler, R. S., Hale, A., Strasser, T. A. and Burdge, G. L., "Cladding-mode resonances in hybrid polymer-silica microstructured optical fiber gratings," IEEE Photonics Technol. Lett.12(5), 495 - 497 (2000).

[19] Granzow, N., Uebel, P., Schmidt, M. A., Tverjanovich, A. S., Wondraczek, L. and Russell, P. St. J., "Bandgap guidance in hybrid chalcogenide-silica photonic crystal fibers," Opt. Lett. 36(13), 2432-2434 (2011). 
[20] Petersen, C. R., Møller,U., Kubat, I., Zhou, B., Dupont, S., Ramsay, J., Benson, T., Sujecki, S., Abdel-Moneim,N., Tang, Z., Furniss, D., Seddon, A. and Bang, O., "Mid-infrared supercontinuum covering the 1.4-13.3 $\mu \mathrm{m}$ molecular fingerprint region using ultra-high NA chalcogenide step-index fibre," Nat. Photonics 8(11), 830-834 (2014).

[21] Markos, C., Yannopoulos, S. N., and Vlachos, K., "Chalcogenide glass layers in silica photonic crystal fibers," Opt. Express 20(14), 14814-14824 (2012).

[22] Markos, C., Kubat, I., and Bang, O., "Hybrid polymer photonic crystal fiber with integrated chalcogenide glass nanofilms," Sci. Rep. 4, 6057 (2014).

[23] Markos, C., "Thermo-tunable hybrid photonic crystal fiber based on solution-processed chalcogenide glass nanolayers," Sci. Rep. 6, 31711 (2016).

[24] Abouraddy, A. F., Bayindir, M., Benoit, G., Hart, S. D., Kuriki, K., Orf, N., Shapira, O., Sorin, F., Temelkuran, B. and Fink, Y., "Towards multimaterial multifunctional fibres that see, hear, sense and communicate," Nat. Mater. 6, 336-347 (2007).

[25]Bayindir,M., Sorin, F., Abouraddy, A. F., Viens, J., Hart, S. D., Joannopoulos, J. D. and Fink Y., "Metal-insulatorsemiconductor optoelectronic fibres," Nature volume 431, 826-829 (2004).

[26] Kaufman, J. J., Tao, G., Shabahang, S., Deng, D. S. Liang, X., Johnson, S. G. Fink, Y. and Abouraddy, A. F. "Structured spheres generated by an in-fibre fluid instability," Nature 487 (7408), 463-467 (2012).

[27] Schneider, F., Draheim, J., Kamberger, R. and Wallrabe, U., "Process and material properties of polydimethylsiloxane (PDMS) for Optical MEMS," Sens. Actuators A Phys. 151(2), 95-99 (2009).

[28] Markos, C., Vlachos, K. and Kakarantzas, G., "Guiding and birefringent properties of a hybrid PDMS/silica photonic crystal fiber," Proc. SPIE 7914, 791427 (2011).

[29] Markos, C., Vlachos, K. and Kakarantzas, G., "Guiding and thermal properties of a hybrid polymer-infused photonic crystal fiber," Opt. Mater. Express 2(7), 929-941 (2012).

[30] Markos, C., Antonopoulos, G. and Kakarantzas, G., "Broadband Guidance in a Hollow-Core Photonic Crystal Fiber with Polymer-Filled Cladding," IEEE Phot. Tech. Lett. 25(20), 2003 - 2006 (2013).

[31]Zha, Y., Waldmann, M. and Arnold, C. B., "A review on solution processing of chalcogenide glasses for optical components," Opt. Mater. Express 3(9), 1259-1272 (2013)

[32] Borzycki, K. and Schuster, K. [Photonic Crystals - Introduction, Applications and Theory] InTech, 175-200. (2012).

[33] http://www.vitron.de/english/IR-Glaeser/vitronprv.seq 